\title{
RELIABILITY OF BLADDER VOLUME DETERMINATION IN CHILDREN BY PORTABLE ULTRASONOGRAPHIC SCANNER IN STANDING POSITION
}

\author{
TANER CEYLAN ${ }^{1}$, Hasan Serkan Dogan ${ }^{2}$, Burak Citamak ${ }^{3}$, Kamranbay Gasimov ${ }^{3}$, Ali \\ Cansu Bozaci ${ }^{2}$, Vasileios Tatanis ${ }^{2}$, and Serdar Tekgul ${ }^{3}$ \\ ${ }^{1}$ Affiliation not available \\ ${ }^{2}$ Hacettepe University Faculty of Medicine \\ ${ }^{3}$ Hacettepe University
}

April 14, 2021

\begin{abstract}
Aim: We aimed to compare pre-voiding bladder and post-voiding residual (BV, PVR) volumes measured by portable ultrasonic scanner (PUS) in standing and supine positions. Material and Methods: A total of 436 children were included. We composed 2 groups (group-1: PUS vs. volume by catheter, group-2: PUS vs. infused volume during urodynamic study) to evaluate the agreement of PUS measurements with actual bladder volume and then third group (group-3) to analyze the correlation of PUS measurements in standing vs. supine positions. In groups 1 and 2, agreement of measurements were evaluated by paired sample $\mathrm{T}$ or Wilcoxon signed rank tests. Following confirmation of agreement, correlations were analyzed by Pearson's or Spearman's coefficients in all groups. Interpretation of coefficients were done as 0.90-1.00 (very high correlation) and 0.70-0.90 (high correlation), respectively. Results: In group-1, measurements (catheter vs. PUS) were similar (Wilcoxon Signed rank test, $\mathrm{p}=0.976)$ and were highly correlated $(\mathrm{r}=0.873)$. In group-2, measurements of bladder volumes infused by urodynamic device and volumes by PUS were similar that revealed the agreement of PUS measurements on different volumes and highly correlated at the 25 th and very highly correlated at the 50th, 75th and 100th percentiles of the EBC (estimated bladder capacity related to age). In group-3, BV and PVR measurements by PUS in standing and supine positions were highly correlated that revelaed PUS can be used in both positions. Conclusion: Measurements of BV before uroflowmetry or PVR volume by PUS in standing position gave similar results with those in supine position.
\end{abstract}

\section{Hosted file}

Main document- updated.pdf available at https://authorea.com/users/407730/articles/517970reliability-of-bladder-volume-determination-in-children-by-portable-ultrasonographicscanner-in-standing-position

\section{Hosted file}

Tables.pdf available at https://authorea.com/users/407730/articles/517970-reliabilityof-bladder-volume-determination-in-children-by-portable-ultrasonographic-scanner-instanding-position 